\title{
Exploring Pre-Service Teachers' Previous Knowledge on Fundamental Physical Quantities of Measurement
}

\author{
Anna Mwinbuabu Naah ${ }^{1}$, Valentina Osei-Himah ${ }^{2}$ \\ ${ }^{1}$ Offinso College of Education, Ghana \\ ${ }^{2}$ Atebubu College of Education, Ghana \\ Corresponding Author: Valentina Osei-Himah
}

\begin{abstract}
This study explored pre-service teachers' previous knowledge on the measurement of some basic quantities and how they are applied in real life situations. A quantitative descriptive cross-sectional survey research design was adopted and data gathered using a close ended questionnaire. A total of 315(females 105; males 210) pre-service teachers participated in the study. All participants were on the Four-Year B.Ed. Primary Education Programme offering General Biology, General Chemistry and General Physics as core courses. Analysis of the data showed that the pre-service teachers had wrong knowledge of SI units of measurement for these basic quantities. They were in particular unable to identify the SI unit symbols for Time, Mass and Length - practically exchanging upper case letters with lower case ones. They were however able to identify and correctly match measuring devices with their corresponding basic quantities. They could also correctly link these measuring devices to real life situations. Thus, though their knowledge of the SI units for the basic quantities was limited, their previous knowledge about them and their measuring devices was good. The study laid bare the significance of assessing pre-service teachers' previous knowledge. Such assessment exposes the teacher to learner needs, strengths and weaknesses. It also guides and equips the teacher on 'what' and 'how' to plan lessons for new learning concepts to be effectively delivered in a new learning environment. It was therefore recommended that learners' prior knowledge should always be revised before
\end{abstract}

introducing them to new learning concepts and activities.

Keywords: Pre-service teachers' previous knowledge, Fundamental physical quantities of measurement, SI units of measurement

\section{INTRODUCTION}

Being a developing nation Ghana has since independence, had a series of educational reforms under successive governments. These reforms have invariably sought to address systemic deficiencies to enable education respond to the goals and aspirations of the people within the context of challenges imposed by an ever-changing global environment. Consequently, the reforms have always come with policy change in direction, focus and reorientation. There has also always been a general revamping of organizational structure. Over time, the reforms have thus served as game changers that promote civilization growth, industrialization and an overall national development. The very first reform following self-rule was the Education Ordinance of 1951, which formed part of Nkrumah's Accelerated Development Plan (ADP). Ten years later the first legislated exclusive reform for a free and compulsory primary education was enacted - Education Act of 1961 (Act 87), and pursued. Then in 1966, under the rule of the National Liberation Council (NLC), 
came the introduction of Continuation Schools pursuant to recommendations from the Kwapong Review Committee. From then the country had to wait until 1987 for the next major reform that ushered in the Junior Secondary School (JSS) Programme. The JSS concept was a key recommendation from the Dzobo Educational Reform Committee established in 1972 by the National Redemption Council (NRC). The Free Compulsory Universal Basic Education (fCUBE) Programme that followed in 1995 was to respond to a provision in the 1992 Constitution. Then by an act of Parliament in 2008 (Act 778) based on the Anamoah Mensah Review Committee Report the country introduced another reform that year. This persisted until the recent reforms of 2019 bringing on board at the primary level what is known as the Common Core Programme (CCP).

Of relevance to this study is how these reforms have contributed to tweaking aspects of the education system of the country, including access, content, structure and governance in different ways. Like other subjects the study of Science has been seriously affected by the ever changing reforms. Positively, it is significant to note how invariably the reforms placed the study of Science among subjects of priority that drive the nation's engine of growth and development. Each reform placed emphasis on Science as a subject to be studied by all students and at all levels of the pre-tertiary system. From the primary through junior high to the senior high school level, the study of Science has since been compulsory, at least as a core subject. The content matter of the subject at these levels has always been typically crafted to help develop students' innate sense of curiosity, creativity and critical thinking. The intention has also been to develop skills and habits of mind and attitudes necessary for scientific inquiry (MOE, 2007; MOE, 2019). The content embodies practical use of concepts and the need to treat resources of the world with a humane and responsible attitude. For reasons yet to be appreciated by all, Science has been studied under various names from one reform to the other. Prior to the 1987 reforms, Science was referred to as General Science. While it maintained the same name at the Junior Secondary School (JSS) level during the reforms it was referred to as Core Science at the Senior Secondary School (SSS) level. These names were however changed during the 2008 reforms to Integrated Science at the Upper Primary, Junior High School and Senior High School levels. At the Lower Primary level however, it was known as Natural Science. Currently under the 2019 reforms at the Primary level Science is called Science for lower Primary and Integrated Science for the Upper Primary level (MOE, 2019).

The reforms also focused on content of the subject with respect to importance and relevance to contemporary national needs. This led to the modification, tweaking or total removal of some concepts of the subject. Some concepts or topical areas, including Measurement, have however remained intact throughout all the educational reforms. This fact underlines how important the concept of measurement is in national development. The immergence and utilization of systems of measurement in diverse fields have indeed been us throughout human existence. Comparisons between quantities are made possible by some mutual local agreements among trading partners or collaborators. Thus, measurement has served as foundation to Trade, Science, Technology, and quantitative research. As fundamental as it is to the many things humans do, measurement is unequivocally an elixir of life. In Ghana, as it stands, measurement is topically taught at all levels of the pretertiary education. It is taught from Basic 1 to Basic 6. It is also taught in all classes at the JHS, the SHS as well as in Colleges of Education. At these various levels however, the topic is designed and organized spirally such as to enable delivery of its concept in a gradual but increasing complexity in content and difficulty up the ladder. The idea is to assist students gradually grasp and utilize 
the concept as fundamental knowledge in real life situations.

Having moved up the education ladder to the tertiary level, it is assumed therefore that every student in Ghana, including those offering the Primary Education Programme in the Colleges of Education, must necessarily have some basic knowledge about measurement. This is anchored on the principle that learners of all shades enter new learning environments with some form of experiences and knowledge acquired from previous environments in the learning value chain. The experiences and knowledge so acquired, called 'Previous Knowledge', influence what is to be taught and learned in the new learning environment. It is possible that this previous knowledge could be a pack of misconceptions that would significantly interfere with the new concepts to be taught and learned. This study therefore set out to discover whether indeed such misconceptions exist by accessing the previous knowledge of pre-service teachers and to further probe their effect on teaching new topics. In all academic endeavour learners have their own idiosyncrasies. These differences could stem from their home background and even along the journey from their homes to the classroom (Diaz, 2017). Learners imbibe a broad-range of pre-existing attitudes, skills, beliefs and knowledge from experiences differently. And as they see things from different perspectives so also could they receive, understand and organize knowledge differently in a new learning environment. Yet by the principle of transfer of training, learners are expected to apply knowledge from one learning experience to another along the education ladder. This is important to both learners and teachers because in teaching, the latter is required to build on the former's previous knowledge of concepts - a pedagogical principle termed 'teaching from the known to the unknown'. Indeed, previous knowledge has extensively been considered the most significant factor influencing learning and student achievement (Hailikari, Nevgi \& LindblomYlänne 2007). It is defined as a multidimensional and hierarchical entity that is dynamic in nature and consists of different types of knowledge and skills. The quality and depth of prior knowledge positively impact on both knowledge acquisition and the capacity to apply higherorder cognitive problem-solving skills. Previous knowledge is an essential part of learning. It is seen as the springboard from which a learner may jump into another topic. Likewise, it is the mesh that connects, links, relates, associates new information, thereby reconstructing into a new and improved knowledge (Diaz, 2017).

Bartlett (1995) is of the view that the formation of new cognitive schema to gain new knowledge depends critically on previous knowledge. This is mostly found to have a strong effect on students' learning and performance. Previous knowledge is a subject characteristic, and learners with more previous knowledge could have a more working memory capacity available to process their current learning activities (Mihalca et al. 2011). Other researchers such as Bartlett and Yeh et al. assert that according to Cognitive Load Theory, an important factor in the learning process is previous knowledge (cited in Dong, SiuYung \& King, 2020). This helps to lessening cognitive load focusing on good learning performance (van Riesen et al., 2019) making it to interacts with other variables in order to influence learning outcomes (Shapiro, 2004). Recent studies on learning advocate that learning is determined by what the learner already knows about the topic or related topics (Svinicki, 2004) and learner's prior knowledge is an essential pre-requisite for learning (Ormrod, 2012). Meaningful and lasting learning is enhanced by linking everyday experiences with classroom topics and purposely engaging prior knowledge with new classroom. Learning initiates with the known and proceeds to the unknown.

There are various purposes for assessing prior knowledge of learners. 
These include identifying learners who are challenged with their studies; determining an appropriate level at which to start the course; provision of feedback to learners; bridging the gap between instructors' expectations and learners' actual knowledge base; and grouping learners according to their abilities for tasks (Hailikari et al., 2008). Also, students who possess relevant and deeper level prior knowledge from previous courses are more likely to get good final grades.

In a study on the influence of prior knowledge on the effectiveness of guided experiment design, van Riesen et al. (2019) found out that prior knowledge influences the degree to which learners benefit from different types and levels of support. They further indicated that the match between effective guidance for inquiry learning in an online environment and prior knowledge is a very delicate matter that should be treated with care. Thus, instructors can adjust guidance based on learners' prior knowledge and behaviour. Furthermore, findings from a study titled 'How do Prior Knowledge Influence Learning Engagement; the Mediating Roles of Cognitive Load and Help-Seeking' indicated that learning engagement is strongly influenced by prior knowledge (Dong et al., 2020). They also indicated that cognitive load plays a crucial role in the relationship between prior knowledge and learning engagement via help-seeking behaviors. Learners who least need help because they already know more (high prior knowledge) are also more likely to engage in adaptive instrumental help-seeking. Ultimately, learners who most needed help because they know less (low prior knowledge) are less likely to seek help or seeking or engage in executive help-seeking (Dong et al., 2020).

Misunderstanding of concepts prevents learners from making the appropriate connections between other concepts (Jonte, Carstensen, \& Holmberg, 2011). Concepts need not to be covered until learners reach a level of understanding that allows them to make sense of the material they learn and deepen their understanding as they move forward (Land, Meyer, \& Smith, 2008). To understand a new concept being taught and use it to synthesize new knowledge, learners need to apply their prior knowledge. When learners struggle with concepts they learn, instructors attempt to remedy the situation using a variety of methods at their disposal (Ionas, Cernusca, \& Collier 2012). A study conducted by Ionas et al. (2012) revealed that there was a moderating effect of prior knowledge on the effectiveness of selfexplanation for Chemistry problem-solving. That is, the interaction between prior knowledge of Chemistry and the effectiveness of self-explanation was seen to be in twofold. The use of strategies based on self-explanation tends to help learners better incorporate their prior knowledge in their current activities by "forcing" them to consider it when on task. Research findings by Hailikari et al. (2008) from a study on the relevance of prior knowledge in learning and instruction design showed that prior knowledge assessment that happens at the beginning of a course may be an important tool for instructional support. They further explained that assessing prior knowledge makes it possible to identify learners who are struggling with their studies. However, prior knowledge assessment alone is not enough as learners need to be provided with feedback on their performance and instructors must be aware of how the assessment results can be used in designing instructions.

Inadequate previous knowledge hinders many learners in their effort to extract meaning from teaching. Most times, teachers think learners come to class having all the skills and the requisite information to learn what they teach. This way of thinking is specious as learning is influenced by learners' previous knowledge which serves to anchor instructional concepts by creating mental hooks that facilitate learning. Consequently, the new concept learnt could be confusing when it conflicts with learners' pre-existing misinformation; i.e. new 
concept to be grasped by the learner may be distorted (Via, 2016). This implies that previous knowledge can lead to success or failure in the classroom (David, 2017).

Instructors in higher educational institutions are faced with a common problem of students lacking the necessary prior knowledge and skills as they enter for more advanced courses in the curriculum (Batchelor, 2004 and Kelly \& Glaspole, 2006). In planning their course outline or lesson to be delivered, every teacher as of routine should be guided by the following two questions in the effort effectively take advantage of learners' previous knowledge.

i. What do my students already know about the topic?

ii. What kind of questions, prior knowledge tests or non-graded assessments can I use to find out my students' prior knowledge?

It was thus in conformity with the above consideration that the study was fashioned to explore the knowledge of selected pre-service teachers in a College of Education on some fundamental units of measurement. The study was guided by the following research questions;

i. What are pre-service teachers' previous knowledge on basic physical quantities and their SI units of measurement?

ii. How do pre-service teachers' link their previous knowledge on SI units of measurement of some basic physical quantities with symbols of the units?

iii. What are pre-service teachers' previous knowledge on measuring devices used for some basic physical quantities?

iv. How do pre-service teachers apply their previous knowledge on the measurement of some basic physical quantities to real life situation?

\section{METHODS}

The study set out to explore preservice teachers' pervious knowledge on some physical measurement quantities and how the teachers apply it in real life situation. A quantitative descriptive cross- sectional survey research design was adopted for the study. The choice for this method was based on the nature and purpose of the study. Indeed, the descriptive cross-sectional survey design method is an effective approach in gathering data about content knowledge from a population sampled (Creswell, 2013) as it provides accurate description of the character under study. The research instrument used to gather the data was a close ended questionnaire. The items on the instrument were self-developed by the researcher. In order to establish face and content validity and hence forestall ambiguity, experts at the Department of Science and Physical Education at the College, read through the items on the questionnaire. A pilot-study was conducted to determine the feasibility ratings and reliability of the instrument. This was to ascertain whether the instrument was measuring what it was supposed to measure. Pre-service teachers in a College of Education, affiliated to the University of Cape Coast, in the Bono East Region, were sampled and used for the pilot-study. All respondents from the college were 4 Year B.Ed. Primary Education students who offered General Biology, Chemistry and Physics as core courses in the first and second years of their study. It was assumed the sampled students had similar characteristics as those at the College in the Ashanti Region where the actual study took place. All selected participants for the pilot study were holders of the West Africa Senior School Certificate Examination (WASSCE) and the Basic Examination Certificate (BEC).

Primary data were collected using a closed-ended questionnaire. The data were analysed using SPSS version 21 . The study employed Cronbach's alpha to test the internal consistency and reliability of the questionnaire for each item. The Cronbach's alpha values were as follows:

(i) Content knowledge on basic quantity units and symbols (0.70); 
Anna Mwinbuabu Naah et.al. Exploring pre-service teachers' previous knowledge on fundamental physical quantities of measurement.

(ii) Basic quantity measuring device and (0.75);

(iii)Application of basic quantity (0.71).

From the analysis of data in the pilot-study, some of the items with negative reliability were deleted whiles others with negative wordings were reframed to make them reliable.

A total of 315 pre-service teachers (female 105; male 210) participated in the actual study. There were all pre-service teachers on a 4 year B.Ed. Primary Education Programme offering General Biology, General Chemistry and General Physics as core courses for the four-year duration. Purposive sampling, a type of nonprobability sampling technique was employed to select the respondents. This sampling method was adjudged the most suitable given that the groups of those involved were considered the right people to provide useful information for the study.

Before administering the questionnaire to respondents, the Head and members of the Department of Science and Physical Education at the College of Education were formally informed of the intention to undertake the survey and permission was duly sought to use the students. The instrument was then administered directly to the pre-service teachers in their various lecture rooms. All questionnaires administered were personally collected by the researcher. Responses from participants were then coded, scored and scores entered into the computer. Descriptive and frequency statistics were carried out on the data using the Statistical Package for Social Sciences (SPSS) software version 21.

\section{RESULTS}

The study explored pre-service teachers' previous knowledge on the measurement of some physical quantities and their application to real life situation. Descriptive and frequencies statistics were carried out on the data collected using SPSS software version 21 . Tables were provided to illustrate and support the findings. The results from the study were organized and presented under the following sections:
i. $\quad$ Pre-service
Teachers' Previous
Knowledge on the SI Units of Measurement of some Basic Physical Quantities.

ii. Pre-service Teachers' Previous Knowledge on the SI Unit Symbols of Measurement for some Basic Physical Quantities.

iii. Pre-service Teachers' Previous Knowledge on Measuring Devices of some Basic Physical Quantities.

iv. Pre-service Teachers' Previous Knowledge on some Basic Physical Quantities and Application of their Measurement to Real Life Situation

\section{Demographics}

A total of 315 Pre-service teachers participated in the study. This number comprised 105 females and 210 males. They were all first year pre-service teacher trainees admitted into the college's 4 year B.Ed. Primary Education Programme with General Biology, General Chemistry and General Physic as core courses. The ages of the pre-service teachers ranged from 17 to 30 years with an average age of approximately 23 years. The Pre-service teachers had some prior knowledge on measurement as a topic from their study of Integrated Science at the Junior and Senior High School levels. Each had at least a credit pass in the subject at the Senior High School before gaining admission into the College of Education. General Biology, Chemistry and Physics were core courses pursued only by Primary Education students. General Biology and General Chemistry were offered during the first year whiles General Physics was offered in the second year.

\section{i). Pre-service Teachers' Previous Knowledge on the SI Units of Measurement of some Basic Physical Quantities.}

Table 1, displays results of the preservice teachers' previous knowledge on the 
Anna Mwinbuabu Naah et.al. Exploring pre-service teachers' previous knowledge on fundamental physical quantities of measurement.

SI units of measurement of some basic physical quantities. The respondents were asked to indicate the correct option by ticking the SI unit that corresponded with the basic quantity. Out of the 315 respondents only 50 (15.9\%) of them expressed a good knowledge of the basic quantity for Mass. With regards to the basic quantity for Length and Temperature, 55 (17.5\%) and 52 (16.5\%) of the respondents respectively had the answer correct. A good number of the respondents (134) had knowledge of the SI units of time. This however fell short of 50 per cent of the total number of respondents for the study. Fortytwo or 13.3 per cent of the respondents had the basic quantity of electric current right indicating a good knowledge of the concept. Generally, it was observed that majority of the pre-service teachers had wrong or misconceived previous knowledge on the SI units of measurement of some basic physical quantities.

Table 1: Frequency Distribution of Pre-Service Teachers' Previous Knowledge on the S.I Units of Measurement of Some Basic Physical Quantities (n = 315)

\begin{tabular}{|l|l|l|l|l|l|l|l|l|l|}
\hline Mass & Freq & Length & Freq & Temperature & Freq. & Time & Freq & Electric current & Freq \\
\hline kilogram & 187 & meter & 166 & kelvin & 153 & Minute & 103 & ampere & 176 \\
\hline kilogram & 50 & meter & 55 & kelvin & 52 & Minute & 23 & ampere & 53 \\
\hline gram & 41 & kilometre & 50 & degree celsius & 53 & Second & 55 & candela & 42 \\
\hline gram & 37 & kilometre & 44 & degree celsius & 57 & Second & 134 & candela & 44 \\
\hline Total & 315 & Total & 315 & Total & 315 & Total & 315 & Total & 315 \\
\hline
\end{tabular}

\section{ii). Pre-service teachers' previous knowledge on the SI Unit symbols of measurement for some basic physical quantities.}

Table 2: Frequency Distribution of Pre-Service Teachers' Previous Knowledge on the S.I Unit Symbols on Measurement of Some Basic Physical Quantities (n = 315)

\begin{tabular}{|l|l|l|l|l|l|l|l|l|l|}
\hline Mass & Freq. & Length & Freq. & Temperature & Freq. & Time & Freq. & Electric current & Freq. \\
\hline Kg & 157 & M & 160 & K & 155 & M & 121 & A & 176 \\
\hline kg & 96 & m & 81 & k & 49 & m & 52 & a & 73 \\
\hline G & 35 & KM & 37 & D & 63 & S & 69 & cd & 35 \\
\hline g & 27 & km & 37 & d & 48 & s & 73 & Cd & 31 \\
\hline Total & 315 & Total & 315 & Total & 315 & Total & 315 & Total & 315 \\
\hline
\end{tabular}

From Table 2 above, the pre-service teachers' previous knowledge on symbols of the SI units of measurement for some basic quantities was explored. There was much improvement in the respondent's responses on the symbols. For instance, out of the 315 respondents 176, 155, 96, and 81 (expressed percentage-wise as $55.9 \%, 49.2 \%, 30.5 \%$ and $25.7 \%$ ) of the pre-service teachers responded correctly to symbols of SI units for the basic quantities of Electric Current, Temperature, Mass and Length respectively. Here the respondents expressed a high previous knowledge of the symbols for the SI units of the basic physical quantities. With regards to the symbol for the basic physical quantity of time, 73 of the respondents expressed knowledge of the SI unit symbol. This fell below $50 \%$ of the total number of respondents for the study.

\section{iii). Pre-service Teachers' Previous Knowledge on Measuring Devices of some Basic Physical Quantities.}

Table 3: Frequency Distribution of Pre-Service Teachers' Previous Knowledge on Measuring Devices for Some Basic Physical Quantities (n = 315)

\begin{tabular}{|l|l|l|l|l|l|l|l|l|l|}
\hline Mass & Freq. & Length & Freq. & Temperature & Freq. & Time & Freq. & $\begin{array}{l}\text { Electric } \\
\text { current }\end{array}$ & Freq. \\
\hline $\begin{array}{l}\text { chemical } \\
\text { balance }\end{array}$ & 243 & $\begin{array}{l}\text { chemical } \\
\text { balance }\end{array}$ & 14 & $\begin{array}{l}\text { Chemical } \\
\text { balance }\end{array}$ & 37 & $\begin{array}{l}\text { Chemical } \\
\text { balance }\end{array}$ & 9 & $\begin{array}{l}\text { Chemical } \\
\text { balance }\end{array}$ & $\begin{array}{l}99 \\
\text { Metre rule }\end{array}$ \\
\hline Thermometer & 3 & Metre rule & 283 & Meter rule & 16 & Metre rule & 2 & Metre rule & 5 \\
\hline Digital clock & 1 & Digital clock & 2 & Digital clock & 13 & Digital clock & 281 & Digital clock & 16 \\
\hline Ammeter & 56 & Ammeter & 3 & Ammeter & 2 & Ammeter & 8 & Ammeter & 194 \\
\hline Total & 315 & Total & 315 & Total & 315 & Total & 315 & Total \\
\hline
\end{tabular}


Anna Mwinbuabu Naah et.al. Exploring pre-service teachers' previous knowledge on fundamental physical quantities of measurement.

From Table 3, the pre-service teachers' knowledge of measuring devices for some basic physical quantities was explored. The respondents were asked to indicate the correct option by identifying the measuring device and ticking the name that corresponded with the basic quantity. The responses indicated the participants had a good practical knowledge on the measuring devices. More than half of them identified the correct and appropriate measuring device for each basic physical quantity.
Specifically, out of the 315 respondents, 283, 281, 247, 243 and 194 for Length, Time, Temperature, Mass and Electric Current respectively. In terms of percentage this would be $89.8 \%, 89.2 \%, 78.4 \%, 77.1 \%$ and $61.6 \%$ respectively. The general observation therefore was that most of the pre-service teachers exhibited having an excellent previous knowledge on the measuring devices of the selected basic physical quantities.

\section{iv). Pre-service Teachers' Previous Knowledge on some Basic Physical Quantities and Application of their Measurement to Real Life Situation}

Table 4: Frequency Distribution of Pre-Service Teachers' Application of Previous Knowledge on Measurement of Some Basic Physical Quantities to Real life Situation $(\mathbf{n}=315)$

\begin{tabular}{|l|l|l|l|l|l|l|l|l|l|}
\hline CIC Rice & Freq. & $\begin{array}{l}\text { Length of } \\
\text { table }\end{array}$ & Freq. & $\begin{array}{l}\text { Temperature of } \\
\text { your body }\end{array}$ & Freq. & $\begin{array}{l}\text { Time for the } \\
\text { next lesson }\end{array}$ & Freq. & $\begin{array}{l}\text { Electric bill at } \\
\text { home }\end{array}$ & Freq. \\
\hline $\begin{array}{l}\text { Chemical } \\
\text { balance }\end{array}$ & 254 & $\begin{array}{l}\text { Chemical } \\
\text { balance }\end{array}$ & 13 & Chemical balance & 3 & $\begin{array}{l}\text { Chemical } \\
\text { balance }\end{array}$ & 2 & $\begin{array}{l}\text { Chemical } \\
\text { balance }\end{array}$ & 81 \\
\hline Metre rule & 3 & Metre rule & 289 & Metre rule & 8 & Metre rule & 3 & Metre rule & 1 \\
\hline Thermometer & 2 & Thermometer & 7 & Thermometer & 301 & Thermometer & 5 & Thermometer & 2 \\
\hline Digital clock & 0 & Digital clock & 4 & Digital clock & 2 & Digital clock & 303 & Digital clock & 5 \\
\hline Ammeter & 56 & Ammeter & 2 & Ammeter & 1 & Ammeter & 2 & Ammeter & 226 \\
\hline Total & 315 & Total & 315 & Total & 315 & Total & 315 & Total \\
\hline
\end{tabular}

Table 4, the pre-service teachers' previous knowledge on some basic physical quantities and application of their measurement to real life situation was explored. The respondents were asked to indicate the correct option by identifying the measuring device and ticking its name to correspond with the correct basic physical quantity provided. Responses indicated that the respondents had adequate knowledge on measuring devices and how they are applied to real life situation. Majority of the respondents identified the correct and appropriate measuring device for each item listed. Correct scores for Time, Temperature, Length, Mass and Electric Current were 303, 301, 289, 254 and 226 respectively. In the same order these translated to very high percentages of $96.2 \%, 95.6 \%, 91.7 \%, 80.6 \%$ and $71.7 \%$. Generally, therefore the pre-service teachers displayed having an excellent previous knowledge on the real-life application measurement in relation to the measuring devices of the selected basic physical quantities.

\section{DISCUSSION AND CONCLUSION}

One way to stimulate effective teaching and learning is to build on what the learner already knows. The previous knowledge of learners influences the 'what' and 'how' the teacher presents concepts in a new learning situation for the learners to assimilate them well. Exploring learners' previous knowledge on concepts before introducing new concepts helps to clear their preconceived ideas about the new concepts to be taught.

This study explored the previous knowledge of pre-service teachers in a College of Education on some fundamental physical quantities in relation to their SI units of measurement, the devices employed to measure them and their applicability in real life situation.

The study results displayed above show that most of the pre-service teachers had wrong knowledge on the S.I units of 
measurement for some basic physical quantities. They could not distinguish between the use of the upper and lower case letters in the spelling of the names of the SI units. They opted for units that started with upper case letters instead of lower case ones. Apart from Time, this wrong notion applied generally for Mass, Length, Temperature and Electric Current.

The respondents appeared to be engaged in a type of lottery or guess work especially when their responses for the unit symbols are compared with those given for the S.I units. It looked more than likely that a respondent that for instance went for Kelvin as S.I unit for Temperature also opted for $\mathrm{K}$ as the symbol Kelvin. This guess work paid out in some instances, making their scores for unit symbols better than the scores for S.I units. There was no obvious indication the pre-service teachers had mastery over the subject matter that was put to them.

This lack of mastery of knowledge on the SI units and their symbols exhibited by the pre-service teachers can be very concerning. Having been taught these concepts right from the basic school level one would have expected higher scores from them in the study. That this did not happen, points to systemic failures, including the production of half-baked teachers. If left uncorrected these pre-service teachers, who would soon be regular teachers in the field could pass on the identified misconceived concepts on Measurement to future learners placed under their tutelage. A vicious cycle of mediocrity could end up being created with a perpetual system of half-baked teachers handling learners who end up becoming half-baked teachers themselves.

This would indeed undermine the aptly conceived idea of maintaining the concept of Measurement in the curriculum across reforms and coming up with a spiral approach that repeatedly takes stock and gradually adds complexity of content to its concept. More efforts need to be exerted to have the topic really well taught and understood by learners at all levels. This is important because when learners do not have strong and relevant previous knowledge from previous learning environments it affects their grasps and understanding of new concepts, hence their performance at current levels they find themselves. This conforms to the assertions by David (2017) and Via (2016) that prior knowledge hinders learning and could distort the learners' view of the new information to be grasped. Instructors should therefore not take learners' prior knowledge on concepts for granted. They need to have a clearer understanding of this previous knowledge and accordingly structure the teaching and learning to suit learner needs.

Whether they are simple, complex, or sophisticated devices are key apparatuses used in science experiments and investigations. Their use is very crucial as it allows for measurement of the quantities of the substances under study. The pre-service teachers did tremendously well identifying the correct and appropriate measuring devices of the basic physical quantities involved. However, their previous knowledge on the devices most likely worked well because these devices are commonly used on a daily basis in measurement. The devices have this become relevant to their everyday activities and that could lead to the high recall. This is reversibly consistent with the Trace Decay Theory of forgetting which states that all memories fade automatically as a function of time. One needs to follow a certain pathway, or trace to recall a memory. If the pathway goes unused for some time the memory decays and leads to inability to recall. Thus, the high ability of the preservice teachers to associate the measuring devices with the appropriate basic physical quantities is likely due to their daily practical usage of them. The daily encounter with the devices solidifies what they have learnt in school about them and thus keeps alive their previous knowledge on them. And as observed by Hailikari, Katajavuori and Lindblom-Ylanne, (2008) learners who 
Anna Mwinbuabu Naah et.al. Exploring pre-service teachers' previous knowledge on fundamental physical quantities of measurement.

possess relevant and deeper prior knowledge from previous courses are likely to get better final grades.

Finally, findings from Pre-service teachers indicated they had good previous knowledge on some basic quantity and their measuring devices on measurement and its application to in real life situation. They expressed mastery of knowledge on the items mostly used at home and the devices used in measuring them. Relating concepts learnt in the classroom to issues of real life is an important goal in the teaching and learning of science (MOE, 2019). This implies the concepts taught on measurement in the previous learning environment were well understood by the learners.

In conclusion, exploring Pre-service teachers' previous knowledge is important in the teaching and learning environment. It exposes the teacher to learners' needs, weakness and their strength. It also guides and equip the teacher on 'what' and 'how' to plan and deliver lesson effectively in new learning environment. Also, the teacher in the classroom plays a vital role in modelling and shaping behaviours of the learners. When Pre-services teachers are thought by always revising their previous knowledge the likelihood that they would imbibe this style of teaching could be high and will put that into practice as they enter the field of work. Future research investigations is needed and required on the various types of previous knowledge exhibited by Preservice teachers at the college level.

\section{Acknowledgement: None}

\section{Conflict of Interest: None}

\section{Source of Funding: None}

\section{REFERENCES}

1. Bartlett. (1995). Remembering: A Study in Experimental and Social Psychology. Cambridge, MA: Harvard University Press.

2. Batchelor, H. (2004). The importance of mathematics diagnostic test for incoming pharmacy undergraduates. Pharm Educ. 4, 69-74

3. Creswell, J. W. (2013). Research design: Qualitative, quantitative, and mixed methods approaches. Sage

Publications, Incorporated.

4. David, M. (2017). Principles of Learning that works. Los Baños: College of Public Affairs and Development, University of the Philippines Los Baños.

5. Diaz, K. V. L. (2017). Prior Knowledge: It's Role in Learning. Retrieved June 5, 2021 from https://www.researchgate.net/publication/33 4291100

6. Dong, A., Siu-Yung, M. J. \& King. B., (2020). How Does Prior Knowledge Influence Learning Engagement? The Mediating Roles of Cognitive Load and Help-Seeking. Frontiers Psychology, 11, 1-10.

7. Hailikari, T., Nevgi, A., \& LindblomYlänne, S. (2007). Exploring alternative ways of assessing prior knowledge, its components and their relation to student achievement: a mathematics- based case study. Stud. Educ. Eval., 33(3), 20-37.

8. Ionas, I. G., Cernusca, D., \& Collier, H. L. (2012). Prior knowledge influence on selfexplanation effectiveness when solving problems: an exploratory study in science learning. International Journal of Teaching and Learning in Higher Education, 24(3), 349-358.

9. Jonte, B., Carstensen, A-Karin, \& Holmberg. M. (2011). "Analytical Tools in Engineering Education Research: The 'Learning a Complex Concept' Model, Threshold Concepts and key Concepts in Understanding and Designing for Student Learning." In Proceedings of Research in Engineering Education Symposium 2011, edited by Wilmar Hernandez, 51-60. Madrid: Universidad Politécnica de Madrid (UPM).

10. Kelly, N. \& Glaspole, S. E. (2006). Formative assessment as a learning aid for pharmacy calculations - a theory based design. Pharm Educ. 6, 27-31.

11. Land, R., Meyer, J. H. F., \& Smith, J. (2008). Threshold Concepts within the Disciplines. University of Michigan: Sense Publishers;

12. Mihalca, L., Salden, R. J., Corbalan, G., Paas, F., and Miclea, M. (2011). 
Anna Mwinbuabu Naah et.al. Exploring pre-service teachers' previous knowledge on fundamental physical quantities of measurement.

Effectiveness of cognitive-load based adaptive instruction in genetics education. Comput. Hum. Beha. 27, $82-\quad 88$.

13. Ministry of Education (MOE) (2007). Teaching syllabus for primary school (primary 1-6). Accra: Curriculum Research and Development Division.

14. Ministry of Education (MOE). (2019). Science curriculum for primary schoool. Cantoment-Accra: National Council for Curriculum and Assessment

15. Ormord, J. E. (2012). Human Learning. (6 $6^{\text {th }}$ ed.). Upper Saddle River, New Jersey, USA: Pearson Education Inc.

16. Shapiro, E. S. (2004). Academic skills problems: Direct assessment and intervention, ( ${ }^{\text {rd }}$ ed.). $\quad$ NewYork:

Guilford Press.

17. Svinicki, M. D. (2004). Learning and Motivation in the Postsecondary Classroom
(JB - Anker) 1st Edition. Jossey-Bass Publisher.

18. van Riesen, S. A., Gijlers, H., Anjewierden, A. A., and de Jong, T. (2019). The influence of prior knowledge on the effectiveness of guided experiment design. Interact Learn Environ, 1-17

19. Via, A. (2016). How does students' prior knowledge affect their learning? Retrieved May 15, 2021 from

https://allegravia.github.io/website/learningandteaching/2016/10/18/howlearningworks-01.html.

How to cite this article: Naah AM, Valentina Osei-Himah. Exploring pre-service teachers' previous knowledge on fundamental physical quantities of measurement. International Journal of Research and Review. 2021; 8(11): 44-54. DOI: https://doi.org/10.52403/ijrr. 20211107 